Deyse Cristina Oliveira Silva ${ }^{1 *}$ José Maria Arcanjo Alves ${ }^{2}$ Sandra Catia Pereira Uchôa ${ }^{3}$ Ataiza de Andrade Sousa ${ }^{1}$ Glauber Ferreira Barreto 4 Cineone Nascimento da Silva ${ }^{4}$

Universidade Federal de Roraima - UFRR Programa de Pós-graduação em Agronomia; BR 174, km 12, Monte Cristo, 69300-000, Boa Vista, RR, Brasil

${ }^{2}$ Universidade Federal de Roraima - UFRR Departamento de Fitotecnia, Av. Cap. Ene Garcês, 2413, Centro, 69304-000, Boa Vista, RR, Brasil Universidade Federal de Roraima - UFRR, Departamento de Solos e Engenharia Agrícola, Av. Cap. Ene Garcês, 2413, Centro, 69304-000, Boa Vista, RR, Brasil

${ }^{4}$ Universidade Federal de Roraima - UFRR Av. Cap. Ene Garcês, 2413, Centro, 69304-000, Boa Vista, RR, Brasil

*Autor Correspondente:

E-mail: deyse_cris@hotmail.com

\section{PALAVRAS-CHAVE}

Manihot esculenta

Adubação potássica

Épocas de avaliação

Fertilidade do solo

\section{KEYWORDS}

Manihot esculenta

Potassium fertilization

Evaluation times

Soil fertility

\title{
Curvas de crescimento de plantas de mandioca submetidas a doses de potássio
}

\author{
Growth curves of cassava plants under different doses \\ of potassium
}

RESUMO: O potássio é considerado o nutriente mais extraído pela mandioca. Dessa forma, sua baixa disponibilidade no solo afeta o crescimento da planta, com reflexos na expansão da área de cultivo e produtividade da lavoura em áreas deficientes deste nutriente. Objetivou-se com o presente trabalho estabelecer curvas de crescimento de plantas de mandioca, cultivar Aciolina, submetidas a cinco doses de potássio em ambiente de savana do estado de Roraima. Utilizou-se o delineamento experimental em blocos casualizados, com quatro repetições, em esquema de parcelas subdivididas. Cinco doses de potássio $\left(0,30,60,120\right.$ e $240 \mathrm{~kg} \mathrm{ha}^{-1}$ de $\left.\mathrm{K}_{2} \mathrm{O}\right)$ foram aleatorizadas nas parcelas e épocas de avaliação $(150,210,270$ e 360 dias após o plantio - DAP) nas subparcelas. As variáveis analisadas: diâmetro do caule, altura da primeira ramificação, altura da planta e características da folha. O crescimento em altura da cv. Aciolina se deu em todos os níveis de adubação com potássio, indicando que o baixo teor de $\mathrm{K}$ restringe o crescimento da planta em altura. Os componentes de crescimento da planta de mandioca, diâmetro do caule, altura da primeira ramificação e altura da planta foram afetados positivamente por doses crescentes de potássio até $240 \mathrm{~kg} \mathrm{ha}^{-1}$. A largura da folha, o número de lóbulos e a relação entre comprimento do lóbulo central pela largura do lóbulo central não são afetados pelas doses de potássio.

ABSTRACT: Potassium is considered the most used nutrient by cassava plants. The low availability of this nutrient in the soil affects individual plant growth and ultimate expansion of the cultivated area as well as crop productivity. The objective of the present work was to establish the growth curves of cassava plants of the cultivar Aciolina submitted to five doses of potassium, grown in a savannah in Roraima. The experiment consisted in a split-splot field layout, using a four-replicate, randomized block design. Five doses of potassium (0, 30, 60, 120 and $\left.240 \mathrm{~kg} \mathrm{ha}^{-1} \mathrm{~K}_{2} \mathrm{O}\right)$ were randomized in the plots and evaluation times (150, 210, 270 and 360 days after planting - DAP) in the subplots. The variables analyzed were: stem diameter, height of first ramification, plant height and leaf characteristics. The increase in height of $\mathrm{cv}$. Aciolina occurred at all levels of fertilization with potassium, indicating that low content of K restricts the growth of the plant in terms of height. The growth components stem diameter, height of the first ramification and plant height were positively affected by increasing doses of potassium up to $240 \mathrm{~kg} \mathrm{ha}^{-1}$. The leaf width, the number of lobes and the ratio between length and width of the central lobe were not affected by potassium. 


\section{Introdução}

A mandioca (Manihot esculenta Crantz) é uma cultura de grande importância nos trópicos, por ser um alimento básico prontamente disponível, por sua facilidade de cultivo e capacidade de se transformar, podendo ser armazenado como alimento por vários anos (Nassar et al., 2009). Apesar de sua importância, a mandioca tem sido relativamente pouco estudada. Nesse sentido, é necessário aumentar as pesquisas sobre esta cultura, para que se possa melhor compreender as alterações fisiológicas, bioquímicas e produtivas ao longo do seu crescimento e desenvolvimento (Albuquerque et al., 2012).

A grande variação morfológica é um importante meio para o reconhecimento de acessos de mandioca, determinação das cultivares com certos atributos similares e identificação de materiais repetidos que receberam nomes diferentes em distintos lugares, em bancos de germoplasma (Campos et al., 2010). Segundo Ramos (2007), a caracterização morfológica pode ser usada por muitos pesquisadores e agricultores como guia do potencial de cada um dos genótipos e ajudar na escolha do melhor material a ser usado.

As características vegetativas e reprodutivas podem ser influenciadas por fatores nutricionais. Dentro desse contexto, o potássio é um dos nutrientes mais importantes para o crescimento das plantas de mandioca, por intensificar o desenvolvimento da parte aérea, teor de carboidratos e proteínas da planta e utilização da água, entre outros fatores que beneficiam significativamente a cultura (Gierth \& Maser, 2007).

Dentre os nutrientes, o potássio é extraído em maior quantidade pela mandioca e sua disponibilidade para as plantas afeta a produtividade da cultura e a qualidade das ramas utilizadas no plantio, baixando a produtividade da lavoura oriunda de ramas obtidas de plantas deficientes em potássio (Otsubo et al., 2007).

$\mathrm{O}$ potássio promove a assimilação de $\mathrm{CO}_{2}$ a síntese de amido e a translocação de carboidratos das folhas para os tubérculos e raízes tuberosas de culturas, onde os carboidratos são o material de armazenamento principal. Em consequência a este fato, ocorre o aumento da produtividade e a melhoria da qualidade de tubérculos (Mehdi et al., 2007).

Embora seja reconhecida a importância do potássio para plantas de mandioca, lacunas acerca do efeito desse nutriente nas características de crescimento da planta elucidam a necessidade de novas pesquisas acerca do assunto. Nesse contexto, objetivou-se com o presente trabalho estabelecer, em diferentes épocas de avaliação, curvas de crescimento das plantas de mandioca "cv. Aciolina", cultivadas na savana de Roraima, submetidas a cinco doses de potássio.

\section{Material e Métodos}

O experimento foi conduzido na área experimental do Centro de Ciências Agrárias da Universidade Federal de Roraima - CCA/UFRR, no Campus Cauamé, no município de Boa Vista, estado de Roraima - Brasil (Latitude de $2^{\circ} 52^{\prime} 20,7^{\prime \prime} \mathrm{N}$, Longitude $60^{\circ} 42^{\prime} 44,2^{\prime}$ 'W e Altitude de $90 \mathrm{~m}$ ), entre outubro/2012 e outubro/2013.

A precipitação média anual é de $1.678 \mathrm{~mm}$, umidade relativa do ar de $70 \%$ e a temperatura diária entre 20 e $38^{\circ} \mathrm{C}$, sendo a média anual de $27,4^{\circ} \mathrm{C}$. Segundo a classificação de Köppen, o clima da região é do tipo Aw, com duas estações climáticas bem definidas, uma chuvosa (abril-setembro) e outra seca (outubro-março). O solo da área experimental foi classificado como Latossolo Amarelo distrocoeso típico (PAdx), de textura Franco-Argilo-Arenosa e relevo suave ondulado. A caracterização química e física da área estudada está apresentada na Tabela 1.

O delineamento experimental adotado foi o de blocos casualizados, com quatro repetições, em esquema de parcelas subdivididas, sendo alocadas as cinco doses de potássio $\left(0,30,60,120\right.$ e $240 \mathrm{~kg} \mathrm{ha}^{-1}$ de $\left.\mathrm{K}_{2} \mathrm{O}\right)$ nas parcelas e quatro épocas de avaliação (150, 210, 270 e 360 dias após o plantio - DAP) nas subparcelas, quando a planta estabeleceu a primeira ramificação. A parcela experimental foi constituída por nove fileiras simples de mandioca com 8,0 metros de comprimento e 6,4 metros de largura, contendo onze plantas. A cultivar de mandioca utilizada foi a Aciolina, por ser a mais plantada no estado de Roraima (Alves et al., 2009; Oliveira et al., 2011).

$\mathrm{Na}$ área experimental, realizou-se a correção do solo com $400 \mathrm{~kg} \mathrm{ha}^{-1}$ de calcário dolomítico (PRNT 100\%), visando elevar a saturação por bases a aproximadamente $55 \%$. O calcário foi aplicado a lanço, sem incorporação. A dessecação das plantas daninhas foi realizada aos 30 dias após a correção do solo.

Tabela 1. Características químicas e físicas do solo nas camadas de 0-20, 20-40 e 40-60 cm de profundidade, coletado antes da instalação do experimento, Boa Vista-RR.

Table 1. Chemical and physical characteristics of the soil at 0-20, 20-40 and 40-60 cm depth, collected before the beginning of the experiment, Boa Vista-RR.

\begin{tabular}{|c|c|c|c|c|c|c|c|c|c|c|c|c|c|}
\hline \multirow{2}{*}{ Camadas } & \multirow{2}{*}{$\mathrm{pH} \mathrm{H} \mathrm{H}_{2} \mathrm{O}$} & $\mathrm{P}$ & $\mathrm{K}^{+}$ & $\mathrm{Ca}^{2+}$ & $\mathrm{Mg}^{2+}$ & $\mathrm{Al}^{3+}$ & $\mathrm{H}+\mathrm{Al}$ & SB & CTCf & $\mathrm{T}$ & V & M & MO \\
\hline & & \multicolumn{2}{|c|}{$\mathrm{mg} \mathrm{dm}^{-3}$} & \multicolumn{7}{|c|}{$\mathrm{cmol}_{\mathrm{c}} \mathrm{dm}^{-3}$} & \multicolumn{2}{|c|}{$\%$} & $\mathrm{~g} \mathrm{~kg}^{-1}$ \\
\hline $0-20$ & 5,43 & 2,15 & 11,5 & 1,09 & 0,25 & 0,19 & 2,5 & 1,38 & 1,57 & 3,88 & 35,2 & 15,5 & 7,3 \\
\hline $20-40$ & 4,68 & 0,60 & 3,0 & 0,48 & 0,10 & 0,39 & 2,9 & 0,59 & 0,98 & 3,49 & 16,9 & 39,8 & 5,3 \\
\hline $40-60$ & 4,98 & 0,40 & 3,0 & 0,44 & 0,10 & 0,29 & 2,6 & 0,55 & 0,84 & 3,15 & 17,5 & 34,5 & 5,3 \\
\hline \multirow{2}{*}{ Camada } & \multicolumn{3}{|c|}{ Areia grossa } & \multicolumn{2}{|c|}{ Areia fina } & \multicolumn{2}{|c|}{ Silte } & \multicolumn{3}{|c|}{ Argila } & \multirow{2}{*}{\multicolumn{3}{|c|}{ Classe textural }} \\
\hline & \multicolumn{10}{|c|}{$\mathrm{g} \mathrm{kg}^{-1}$} & & & \\
\hline $0-20$ & \multicolumn{3}{|c|}{405} & \multicolumn{2}{|c|}{290} & \multicolumn{2}{|r|}{40} & \multicolumn{3}{|c|}{265} & \multicolumn{3}{|c|}{ Franco- Argilo- Arenosa } \\
\hline $20-40$ & \multicolumn{3}{|c|}{360} & \multicolumn{2}{|c|}{290} & \multicolumn{2}{|r|}{40} & \multicolumn{3}{|c|}{310} & \multicolumn{3}{|c|}{ Franco- Argilo- Arenosa } \\
\hline $40-60$ & \multicolumn{3}{|c|}{370} & \multicolumn{2}{|c|}{260} & \multicolumn{2}{|r|}{30} & \multicolumn{3}{|c|}{340} & \multicolumn{3}{|c|}{ Franco- Argilo- Arenosa } \\
\hline
\end{tabular}

P e K - extrator Mehlich-1; Ca, Mg e Al - extrator $\mathrm{KCl} 1$ mol L-1; H + Al - Extrator Acetato de Cálcio 0,5 mol L-1; Matéria orgânica do solo (MO) - Walkley-Black. 
Antes do plantio, as covas foram adubadas com calcário dolomítico (400 kg ha-1 - PRNT 100\%), $80 \mathrm{~kg} \mathrm{ha}^{-1}$ de $\mathrm{P}_{2} \mathrm{O}_{5}$ (fonte - superfosfato simples), $1 / 4$ da recomendação de $\mathrm{N}, 50 \mathrm{~kg} \mathrm{ha}^{-1}$ de $\mathrm{N}$ (fonte - ureia) e 1/3 da recomendação de $\mathrm{K}_{2} \mathrm{O}$ (fonte - cloreto de potássio), conforme as doses estabelecidas para cada tratamento. $\mathrm{O}$ restante da recomendação de $\mathrm{K}_{2} \mathrm{O}$ foi aplicado parcelado em duas coberturas, aos 30 e $60 \mathrm{DAP}$, e o $\mathrm{N}$ em três coberturas, aos 30, 60 e $270 \mathrm{DAP}$. A recomendação de calcário, N, P e micronutrientes foram realizadas com base na análise do solo.

Durante a condução do experimento foram realizadas capinas manuais para o controle das plantas daninhas, levando-se em consideração o período crítico de competição à interferência entre 30 e 75 dias após a emergência - DAE (Albuquerque et al., 2008). Fez-se uso de irrigação complementar, por macroaspersão, entre outubro de 2012 e abril de 2013.

Em cada época de avaliação foram amostradas cinco plantas por parcela experimental, para a coleta das seguintes variáveis: diâmetro do caule (medido a $10 \mathrm{~cm}$ do nível do solo, em $\mathrm{mm}$ ), altura da primeira ramificação (do nível do solo até a primeira divisão, em $\mathrm{cm}$ ), altura da planta (do nível do solo até o nível do dossel da planta, em $\mathrm{cm}$ ); largura da folha (medida entre as extremidades dos dois lóbulos externos da folha, em $\mathrm{cm}$ ); comprimento do pecíolo da folha (medido da base da inserção no caule até a inserção no limbo foliar, em cm); número de lóbulos da folha; comprimento e largura do lóbulo central da folha (maior largura do lóbulo, em cm); relação entre comprimento do lóbulo central pela largura do lóbulo central (CL/LL) e relação entre comprimento do pecíolo pelo comprimento do lóbulo central $(\mathrm{CP} / \mathrm{CL})$. As medidas relacionadas às folhas foram feitas na quinta folha, do ápice para baixo.

Os resultados obtidos foram submetidos à análise de variância e de regressão, a $5 \%$ de probabilidade, empregando o programa SISVAR. Selecionou-se o melhor modelo para expressar o efeito das doses de potássio e das épocas sobre as variáveis avaliadas. O modelo, para cada variável, foi selecionado ao se considerar a significância dos coeficientes dos parâmetros e o maior valor do $\mathrm{R}^{2}$ (Alvarez \& Alvarez, 2006). O teste $\mathrm{t}$ foi utilizado para testar os coeficientes da regressão, a $5 \%$ de probabilidade.

\section{Resultados e Discussão}

De acordo com a análise de variância, a interação entre as doses de $\mathrm{K}_{2} \mathrm{O}$ e épocas de colheita foi significativa $(p \leq 0,05)$ para altura da planta, comprimento do pecíolo e relação entre comprimento do pecíolo e comprimento do lóbulo da folha. Para estabelecer a resposta da planta às épocas de colheita nas diferentes doses de $\mathrm{K}_{2} \mathrm{O}$, realizou-se o desdobramento da interação.

Para as variáveis: altura da primeira ramificação, comprimento e largura do lóbulo da folha foram estudados os efeitos médios para cada fator. $\mathrm{O}$ diâmetro do caule foi afetado apenas pelas doses de $\mathrm{K}_{2} \mathrm{O}$ e as variáveis, largura da folha, número de lóbulos por folha e relação entre comprimento do lóbulo e largura do lóbulo da folha foram afetadas apenas pelas épocas de avaliação.

$\mathrm{O}$ diâmetro do caule teve aumento linear em função das doses de potássio, independentemente da época de avaliação. Dentro do espaço experimental estudado, o maior diâmetro de caule foi de $29,36 \mathrm{~mm}$ na dose $240 \mathrm{~kg} \mathrm{ha}^{-1}$ de $\mathrm{K}_{2} \mathrm{O}$, com incremento de 2,27 mm em relação ao tratamento sem aplicação de K (Figura 1).

Experimentos realizados por Albuquerque et al. (2009) indicaram a importância do diâmetro do caule para a escolha do material de propagação. Manivas selecionadas para a propagação vegetativa apresentaram alta variabilidade no material propagado, por serem oriundas de diferentes partes da planta, consequentemente há variação da quantidade de reservas nutritivas em função do diâmetro.

A altura da primeira ramificação apresentou crescimento linear em função das doses de $\mathrm{K}_{2} \mathrm{O}$ (Figura 2A), sendo observada altura máxima da primeira ramificação de $100,8 \mathrm{~cm}$ na dose de $240 \mathrm{~kg} \mathrm{ha}^{-1}$ de $\mathrm{K}_{2} \mathrm{O}$, logo, cada $\mathrm{kg}$ de $\mathrm{K}_{2} \mathrm{O}$, adicionado ao solo proporcionou uma taxa de incrementos de $0,05 \mathrm{~cm}$ na altura da primeira ramificação. A altura da primeira ramificação pode influenciar o número de manivas e de ramificações.

De modo geral, a competição por fotoassimilados, água e nutrientes aumenta à medida que novas ramificações simpodiais vão surgindo na planta. Pressupõe-se que plantas com maior crescimento na haste principal tenham menor número de ramificação e, assim, maximizem seus fotoassimilidos para região de acúmulo das raízes. Rós et al. (2011) observaram que cultivares de mandioca mais ramificadas apresentaram menor rendimento, além de influenciar negativamente na mecanização da cultura.

$\mathrm{Na}$ Figura 2B, verifica-se que a altura da primeira ramificação apresentou crescimento linear, a partir de $150 \mathrm{DAP}$, porém com baixa taxa de incrementos diários de $0,0192 \mathrm{~cm}$. Aos 150 DAP, a planta já apresentava altura da primeira ramificação de $91,6 \mathrm{~cm}$, sendo acrescidos $4,0 \mathrm{~cm}$ ao longo de 210 dias.

O tipo de ramificação de uma planta de mandioca, seja lateral ou reprodutiva, é importante para a determinação da sua altura, sendo variável com as cultivares. Em algumas, a haste se divide até certa altura em duas, três ou mais ramificações. A fertilidade do solo indiretamente afeta esta característica, já

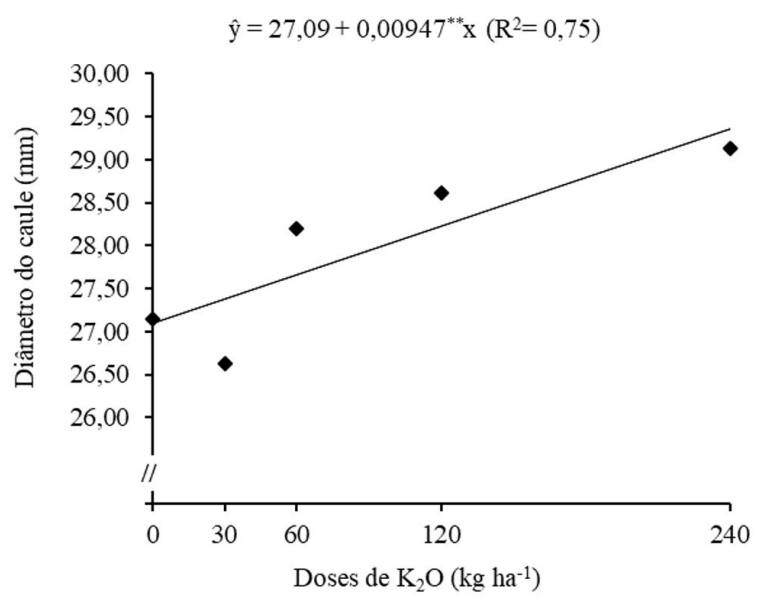

Figura 1. Diâmetro do caule da planta de mandioca cv. Aciolina, em função das doses de $\mathrm{K}_{2} \mathrm{O}$, Boa Vista-RR. **Significativo a $1 \%$ de probabilidade pelo teste $\mathrm{F}$.

Figure 1. Stem diameter of the cassava plant, cv. Aciolina, depending on the doses of $\mathrm{K}_{2} \mathrm{O}$, Boa Vista-RR. **Significant at $1 \%$ probability by test $\mathrm{F}$. 

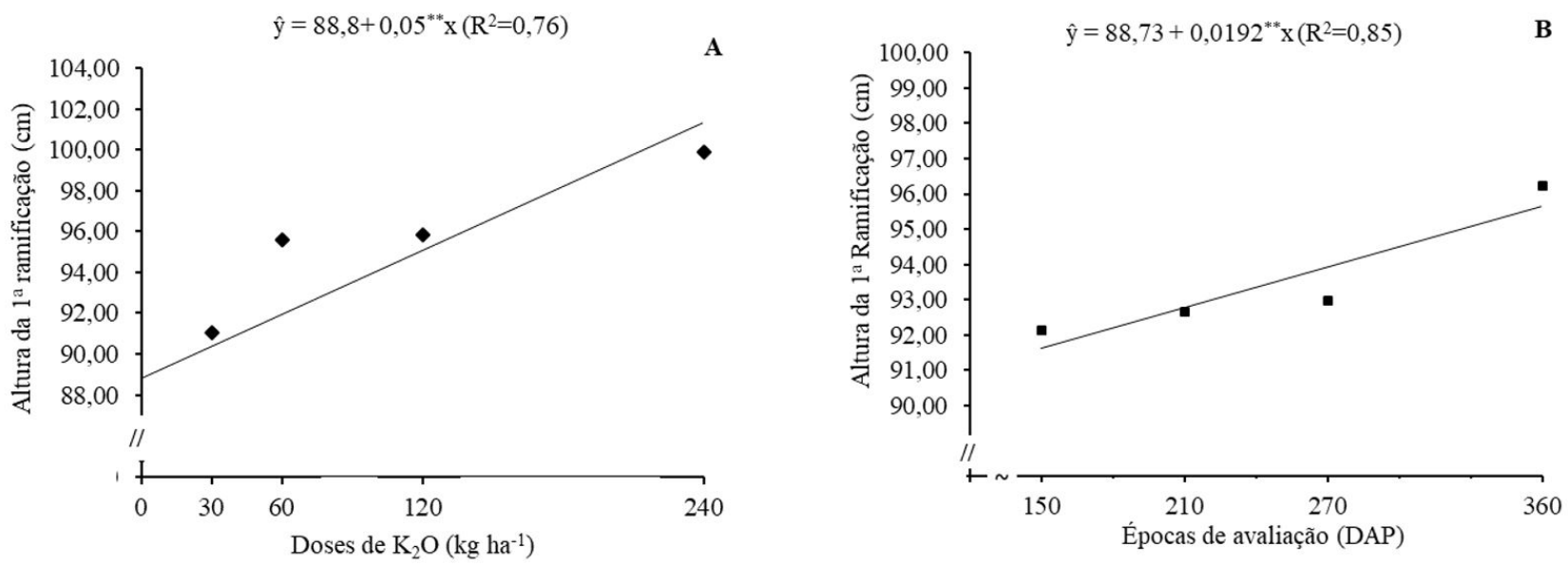

Figura 2. Altura da primeira ramificação da planta de mandioca cv. Aciolina, em função das doses de $\mathrm{K}_{2} \mathrm{O}(\mathrm{A})$ e em função das épocas de avaliação (B), Boa Vista-RR. **Significativo a $1 \%$ de probabilidade pelo teste $\mathrm{F}$.

Figure 2. Height of the first branch of the cassava plant, cv. Aciolina, depending on the doses of $\mathrm{K}_{2} \mathrm{O}(\mathrm{A})$ and according to the evaluation periods (B), Boa Vista-RR. **Significant at $1 \%$ probability by test $\mathrm{F}$.

que em solos de baixa fertilidade as plantas mais ramificadas diminuem o tamanho dos ramos (Carvalho \& Fukuda, 2006).

No desdobramento da interação entre os fatores estudados, verifica-se efeito linear crescente das épocas de avaliação na altura da planta, dentro de cada nível de adubação com $\mathrm{K}_{2} \mathrm{O}$ (Figura 3). Pelos resultados, verifica-se que aos $150 \mathrm{DAP}$ as plantas já se diferenciavam em altura, em resposta aos diferentes níveis de disponibilidade do K no solo. De modo geral, aos 150 DAP a planta já apresentava entre 67 e $75 \%$ da sua altura final, sendo essa proporção maior nas plantas adubadas com K.

$\mathrm{O}$ crescimento em altura da cv. Aciolina se deu em todos os níveis de adubação com potássio, indicando que o baixo teor de $\mathrm{K}$ restringe o crescimento da planta em altura, contrapondo-se aos relatos da literatura sobre a tolerância da planta a baixos níveis de fertilidade (El-Sharkawy, 2012). Isso demonstra que a tolerância da planta a baixa fertilidade deprime a expressão fenotípica, que por sua vez afeta a capacidade produtiva da cultura.

A maior dose de $\mathrm{K}_{2} \mathrm{O}$ determinou plantas $25 \%$ mais altas em relação às não adubadas. Os resultados revelam que $o$ aumento na disponibilidade de $\mathrm{K}$ afeta o porte da planta em altura, sobretudo na fase de acúmulo, antes dos 150 DAP, quando surgem as raízes adventícias. Otsubo et al. (2007), trabalhando com sete cultivares de mandioca no município de Dourados - MS, verificaram que as plantas com as maiores alturas também foram as que tiveram maior produção de parte aérea, mostrando que existe relação direta entre essas duas características. Gomes et al. (2007), caracterizando agronomicamente cem clones de mandioca, demonstraram que a altura da planta foi a única característica da parte aérea que apresentou alto coeficiente de correlação positivo com produção de raízes.

Outros aspectos importantes quanto à altura da planta dizem respeito à competição com plantas infestantes, na escolha de cultivares para consorciação com outras culturas e na definição de espaçamento adequado (Rós et al. 2011). Por outro lado, plantas altas são mais suscetíveis ao acamamento e podem

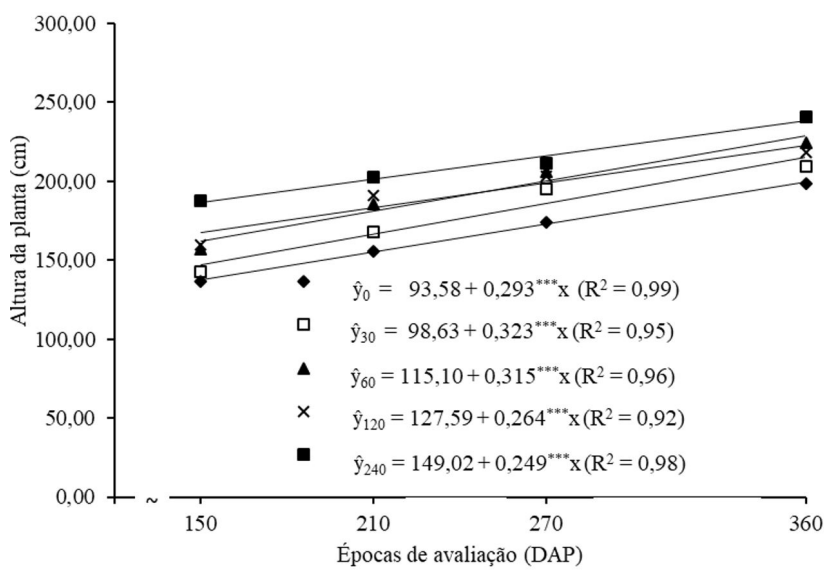

Figura 3. Altura da planta de mandioca cv. Aciolina, em função das épocas de avaliação, para cinco doses de $\mathrm{K}_{2} \mathrm{O}$, Boa Vista-RR. ****Significativo a $0,1 \%$ de probabilidade pelo teste $\mathrm{F}$.

Figure 3. Height of the cassava plant, cv. Aciolina, depending on the evaluation times for five doses of $\mathrm{K}_{2} \mathrm{O}$, Boa Vista-RR. *** Significant at $0,1 \%$ probability by test $\mathrm{F}$.

dificultar o processo de colheita, pois a altura está relacionada à produção de parte aérea e raiz (Gomes et al., 2007).

O modelo linear ajustado para as variáveis de crescimento (diâmetro, altura da primeira ramificação e altura da planta) não permitiu predizer a dose ótima de potássio para a cv. Aciolina, indicando que esta cultivar responde a altos níveis de adubação com $\mathrm{K}$.

A largura da folha e número de lóbulos por folha não foram afetados pelas doses de potássio, com média de $15,73 \mathrm{~cm}$ para largura da folha e 4,63 lóbulos por folha. No entanto, as épocas de avaliação afetaram estas variáveis, cujos dados ajustaram-se a uma função quadrática negativa (Figuras 4A e 4B).

Aos 150 DAP, foi registrada a maior largura da folha, $17,67 \mathrm{~cm}$, e maior número de lóbulos por folha, 5,82. Aos 256 e 288 DAP, a folha apresentou menor largura $(13,66 \mathrm{~cm})$ e o menor número 

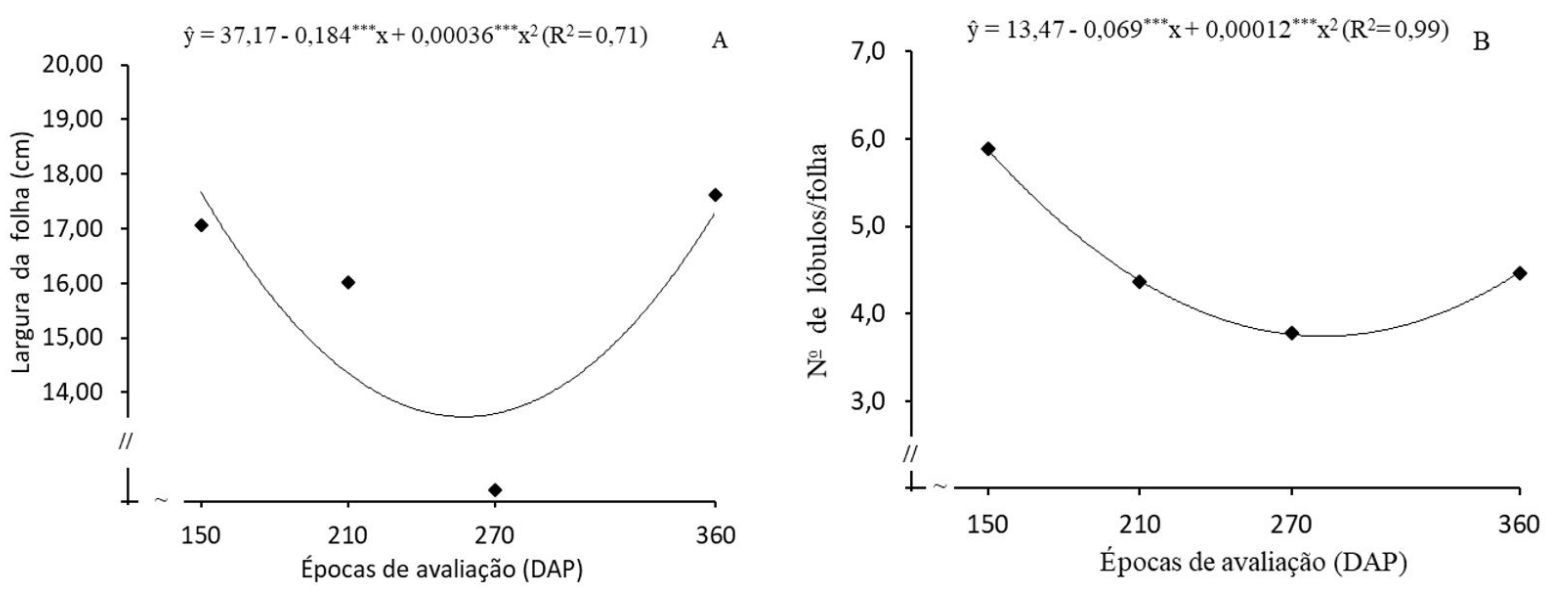

Figura 4. Largura da folha (A) e número de lóbulos por folha (B) da mandioca cv. Aciolina, em função das épocas de avaliação, para cinco doses de $\mathrm{K}_{2} \mathrm{O}$, Boa Vista-RR. *** Significativo a $0,1 \%$ de probabilidade pelo teste $\mathrm{F}$.

Figure 4. Leaf Width (A) and the number of lobes per sheet (B) cassava cv. Aciolina, depending on the evaluation times for five doses of $\mathrm{K}_{2} \mathrm{O}$, Boa Vista-RR. *** Significant at $0,1 \%$ probability by test $\mathrm{F}$.

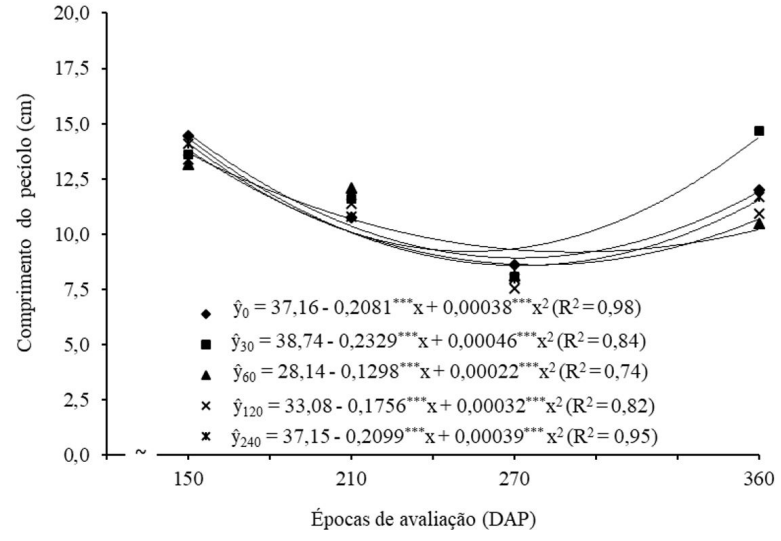

Figura 5. Comprimento do pecíolo da folha de mandioca cv. Aciolina, em função das épocas de avaliação, para cinco doses de $\mathrm{K}_{2} \mathrm{O}$, Boa Vista-RR. *** Significativo a $0,1 \%$ de probabilidade pelo teste $\mathrm{F}$.

Figure 5. Length of cassava leaf petiole, cv. Aciolina, depending on the evaluation times for five doses of $\mathrm{K}_{2} \mathrm{O}$, Boa Vista-RR. $* * *$ Significant at $0,1 \%$ probability by test $\mathrm{F}$.

de lóbulos $(3,55)$, respectivamente. A partir destas datas, há aumentos crescentes nessas características.

Segundo Oliveira et al. (2011), o lóbulo foliar da mandioca é uma característica que contribui para o processo fotossintético. Folhas mais largas e com maior número de lóbulos aumentam a superfície de absorção da luz, favorecem a penetração da luz no interior da copa e seu maior arejamento, resultando em maior acúmulo de fotoassimilados e reservas pela planta. A largura do lóbulo foliar central é um descritor fenotípico muito influenciado pelos efeitos ambientais (Albuquerque, 2007), sendo relevante sua avaliação para as condições locais em situações diversas de fertilidade do solo.

A Figura 5 apresenta os valores para comprimento do pecíolo de plantas de mandioca cv. Aciolina, em função das épocas de avaliação. Pelo desdobramento das doses dentro das épocas, obteve-se resposta quadrática negativa para os diferentes níveis de $\mathrm{K}_{2} \mathrm{O}$ estudados. Independentemente da dose de $\mathrm{K}_{2} \mathrm{O}$, o comprimento do pecíolo diminuiu no intervalo de 253 a 295 DAP; a partir desse intervalo, o comprimento do pecíolo passou a crescer, sendo destacado seu aumento na dose $30 \mathrm{~kg} \mathrm{ha}^{-1} \mathrm{de}_{2} \mathrm{O}$. Provavelmente, esse resultado deve-se a um melhor balanço nutricional entre $\mathrm{N}$ e $\mathrm{K}$.

Os efeitos médios dos fatores estudados para variável comprimento do lóbulo central da folha são apresentados nas Figuras 6A e 6B. Conforme a Figura 6A, o comprimento do lóbulo central da cv. Aciolina em função de doses de potássio apresentou resposta linear decrescente, ou seja, para cada $\mathrm{kg} \mathrm{ha}^{-1}$ de $\mathrm{K}_{2} \mathrm{O}$ adicionado houve redução de $0,004 \mathrm{~mm}$ no comprimento do lóbulo central. Esses resultados, se comparados às variáveis diâmetro do caule e altura da planta (Figuras 1 e 3 ), podem levar a pressupor que adubação potássica estimulou o crescimento em porte da planta em detrimento do crescimento da folha. Na Figura 6B, observa-se que o efeito das épocas para esta característica apresentou comportamento quadrático negativo. Aos 150 DAP, o comprimento do lóbulo central foi de $12,8 \mathrm{~cm}$ e de $9,2 \mathrm{~cm}$ aos $260 \mathrm{DAP}$, passando a partir desta data a apresentar crescimento postivo até a última data de avaliação.

Albuquerque et al. (2009), estudando a caracterização morfológica e agronômica de dez clones de mandioca no estado de Roraima, encontraram variação do comprimento do lóbulo de 11,07 a $19,78 \mathrm{~cm}$, medido aos $210 \mathrm{DAE}$, valores superiores aos encontrados neste estudo até os 360 DAP.

Para a variável largura do lóbulo central da folha não houve interação entre os fatores, sendo estudado o efeito médio de cada fator (Figuras 7A e 7B). O aumento das doses de $\mathrm{K}_{2} \mathrm{O}$ diminuiu linearmente o crescimento da largura do lóbulo central da folha, que na maior dose teve redução de $0,34 \mathrm{~cm}$. Na Figura 7B, observa-se que, em relação às épocas de avaliação, o comportamento dessa variável foi descrito por modelo quadrático negativo. A partir de $150 \mathrm{DAP}$, a largura do lóbulo diminuiu de 3,4 para $2,9 \mathrm{~cm}$ aos $240 \mathrm{DAP}$, quando atingiu seu menor comprimento. 

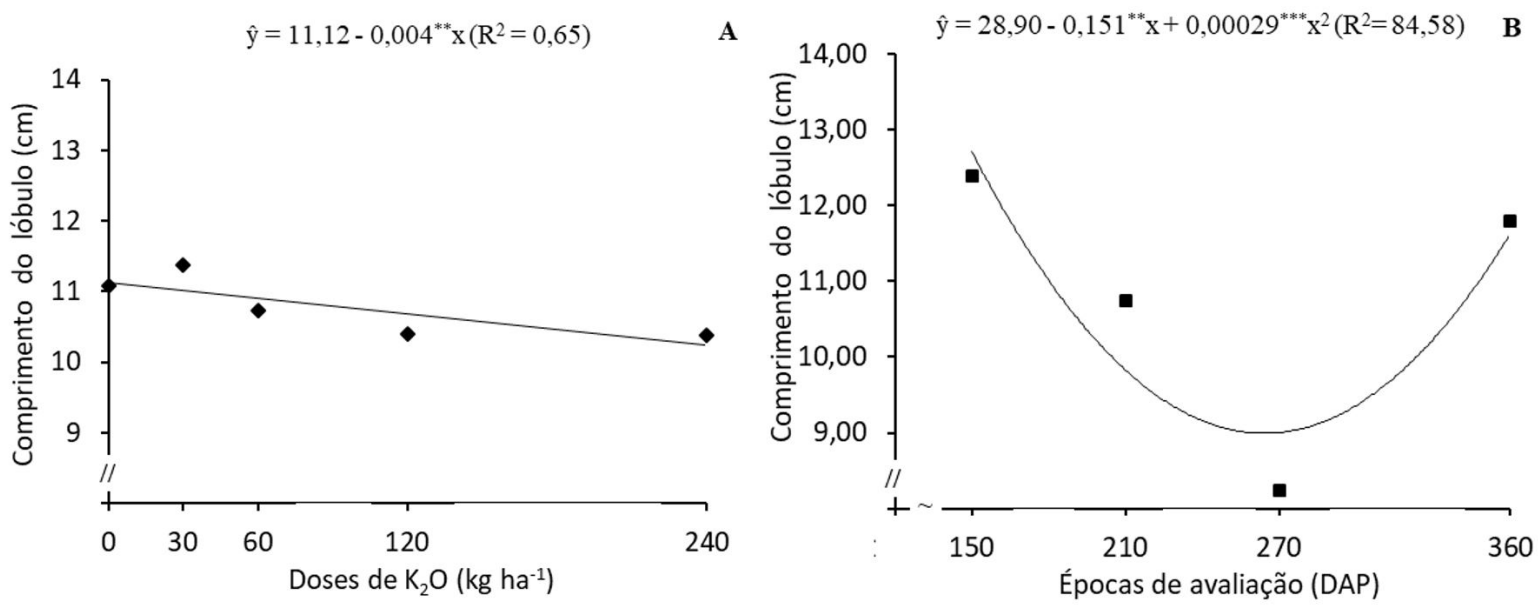

Figura 6. Comprimento de lóbulo central da folha de mandioca cv. Aciolina, em função das doses de $\mathrm{K}_{2} \mathrm{O}(\mathrm{A})$ e em função das épocas de avaliação (B), Boa Vista-RR. **Significativo a $1 \%$ de probabilidade pelo teste $\mathrm{F}$. ${ }^{* *}$ Significativo a $0,1 \%$ de probabilidade pelo teste $\mathrm{F}$.

Figure 6. Central lobe length of cassava leaves, cv. Aciolina, depending on the doses of $\mathrm{K}_{2} \mathrm{O}(\mathrm{A})$ and according to the evaluation periods (B), Boa Vista-RR. **Significant at $1 \%$ probability by test $\mathrm{F}$. ${ }^{* *}$ Significant at $0,1 \%$ probability by test $\mathrm{F}$.
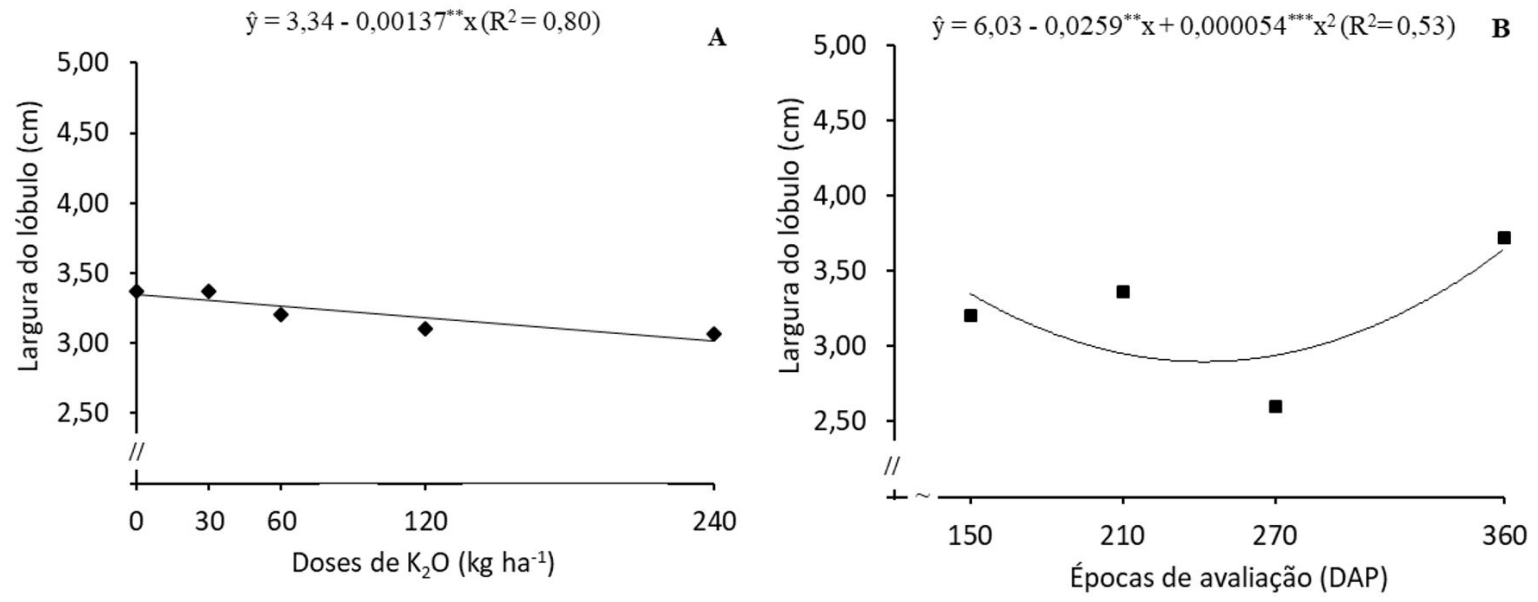

Figura 7. Largura do lóbulo central da folha de mandioca cv. Aciolina, em função das doses de $\mathrm{K}_{2} \mathrm{O}$ (A), e em função das épocas de avaliação (B), Boa Vista-RR. **Significativo a $1 \%$ de probabilidade pelo teste $\mathrm{F}$. ${ }^{*} *$ Significativo a $0,1 \%$ de probabilidade pelo teste $\mathrm{F}$.

Figure 7. Width of the central lobe of cassava leaves, cv. Aciolina, depending on the doses of $\mathrm{K}_{2} \mathrm{O}(\mathrm{A})$, and according to the evaluation periods (B), Boa Vista-RR. **Significant at $1 \%$ probability by test $\mathrm{F}$. ***Significant at $0,1 \%$ probability by test $\mathrm{F}$.

A relação entre comprimento e largura do lóbulo central da folha não foi influenciada pelas doses de $\mathrm{K}$, com média de 3,41 . Valores semelhantes para esta variável foram encontrados por Barbosa (2013), obtendo média de 3,81. A relação entre CL/LL em função das épocas de avaliação foi descrito por modelo quadrático negativo (Figura 8A). O valor mínimo da relação $(2,93)$ se deu aos 309 DAP, e o valor máximo $(3,78)$ foi obtido aos 150 DAP.

Conforme Ledo (2011), quanto maior a relação entre comprimento e largura do lóbulo central da folha de mandioca, maior a taxa fotossintética. Porém, para condições diferenciadas entre plantas, como diferentes níveis de disponibilidade de $\mathrm{K}_{2} \mathrm{O}$, é possível que a importância desta relação seja diminuída em favor de outras variáveis que redundem no porte geral da planta.

$\mathrm{Na}$ relação entre o comprimento do pecíolo $(\mathrm{CP})$ e o comprimento do lóbulo central (CL) em função das épocas de avaliação, observa-se que no desdobramento das doses foi ajustado o modelo quadrático negativo para 0 e $30 \mathrm{~kg} \mathrm{ha}^{-1} \mathrm{de}$ $\mathrm{K}_{2} \mathrm{O}$ e linear decrescente para as demais doses (Figura 8B).

Os tratamentos com as doses 0,60,120 e $240 \mathrm{~kg} \mathrm{ha}^{-1} \mathrm{de}$ $\mathrm{K}_{2} \mathrm{O}$ apresentaram os maiores valores da relação entre $\mathrm{CP} / \mathrm{CL}$ da folha de mandioca aos 150 DAP, com valores de 1,07; 1,09; 1,15 e 1,20, respectivamente. Aos 237,5 e 295 DAP, as doses 30 e $240 \mathrm{~kg} \mathrm{ha}^{-1} \mathrm{de}_{2} \mathrm{O}$, respectivamente, determinaram valor de $\mathrm{CP} / \mathrm{CL}$ de 0,99 (Figura 8B).

Avaliando comprimento do pecíolo e do lóbulo central da folha de mandioca em diferentes épocas de avaliação sob diferentes doses de nitrogênio, verificaram que o comprimento do pecíolo, comprimento do lóbulo central e relação entre o comprimento do pecíolo e do lóbulo central da folha apresentaram comportamento linear decrescente com a idade da planta (entre 120 e 300 DAP), demonstrando que estudos que visam 

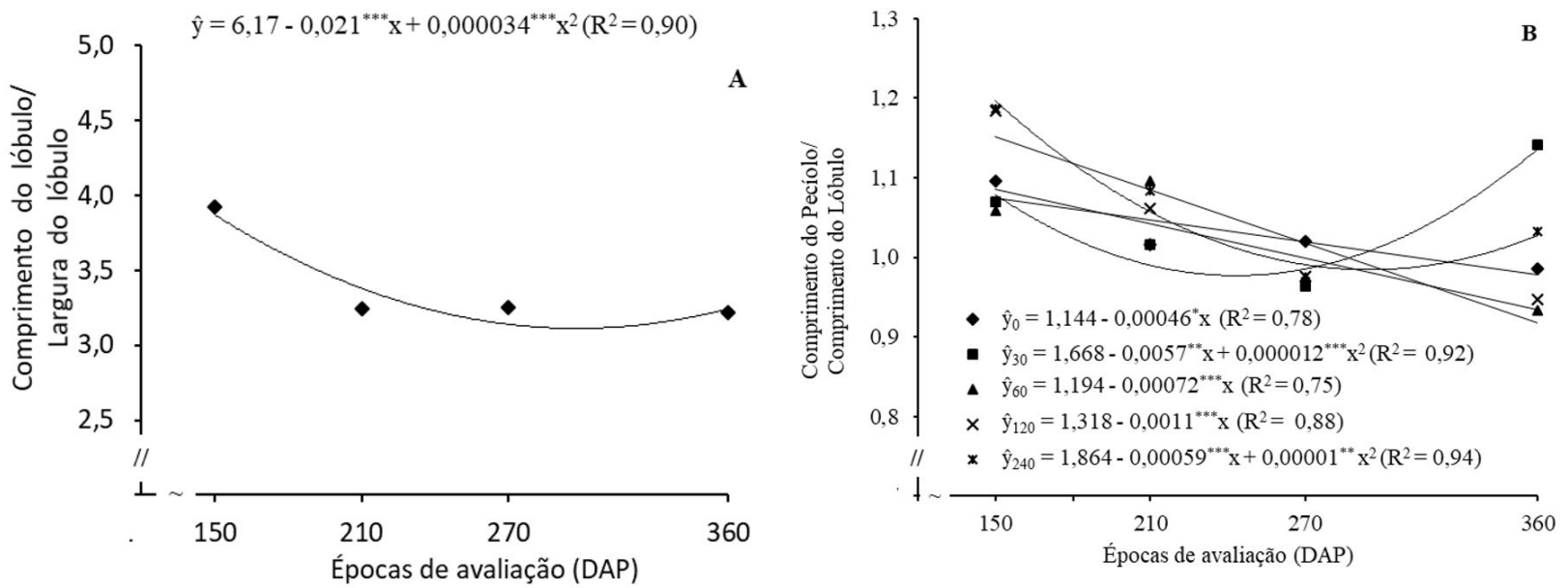

Figura 8. Relação entre comprimento e largura do lóbulo central (CL/LL) (A) e relação entre comprimento do pecíolo e comprimento do lóbulo $(\mathrm{CP} / \mathrm{CL})(\mathrm{B})$ de folhas de mandioca cv. Aciolina, em função das épocas de avaliação, Boa Vista-RR. *Significativo a $5 \%$ de probabilidade pelo teste F. **Significativo a $1 \%$ de probabilidade pelo teste $\mathrm{F}$. ***Significativo a $0,1 \%$ de probabilidade pelo teste $\mathrm{F}$.

Figure 8. Relationship between length and width of the central lobe (LC/LL) (A) and the ratio between length and petiole length of the lobe (PC/LC) (B) cassava leaves cv. Aciolina, depending on the evaluation times, Boa Vista-RR. *Significant at $5 \%$ probability by test $\mathrm{F}$. **Significant at $1 \%$ probability by test $\mathrm{F} . * * *$ Significant at $0,1 \%$ probability by test $\mathrm{F}$.

à caracterização morfológica de folhas da mandioca devem levar em consideração a idade da planta e a disponibilidade de N no solo. Albuquerque et al. (2009) encontraram valores para esta variável que variaram de 0,90 a 1,79 , semelhantes aos resultados encontrados neste trabalho.

A mudança na tendência de diminuição das características da folha (largura da folha, número de lóbulos, largura do lóbulo, comprimento do lóbulo e comprimento do pecíolo) em função das épocas de avaliação pode ser explicada pela adubação nitrogenada realizada aos 270 DAP. A entrada de $\mathrm{N}$ ao sistema desencadeou um processo de inversão do dreno, passando a deslocar fotoassimilados e nutrientes para o rejuvenescimento da parte aérea, tendo as folhas como principais drenos. Relatos na literatura têm indicado que o excesso de $\mathrm{N}$ favorece o desenvolvimento da parte aérea em detrimento das raízes em plantas de mandioca.

Para Falqueto et al. (2009), o crescimento das folhas e, consequentemente, o aumento da massa foliar demonstram que as folhas em desenvolvimento recebem mais fotoassimilados, pois estão incluídas no grupo de drenos metabólicos. Ao longo do desenvolvimento da planta, estas folhas passam a ser fontes, refletindo na mobilização de compostos fotoassimilados para outras partes da planta.

Esses resultados conduzem a questões sobre parcelamento de adubos, ficando evidenciado que coberturas tardias com $\mathrm{N}$ na cultura da mandioca podem afetar negativamente a produção de raízes por inversão do dreno, que passa a ser as folhas.

\section{Conclusões}

Os componentes de crescimento da planta de mandioca, diâmetro do caule, altura da primeira ramificação e altura da planta são afetados positivamente por doses crescentes de $\mathrm{K}_{2} \mathrm{O}$ até $240 \mathrm{~kg} \mathrm{ha}^{-1}$.
A largura da folha, o número de lóbulos e a relação entre comprimento do lóbulo central pela largura do lóbulo central não são afetados pelas doses de potássio.

Para as características de crescimento das plantas de mandioca cv. Aciolina recomenda-se a utilização da adubação potássica de $240 \mathrm{~kg} \mathrm{ha}^{-1}$ de $\mathrm{K}_{2} \mathrm{O}$, uma vez que apresentou os melhores resultados, o que refletirá na produção final de raízes tuberosas.

\section{Referências}

ALBUQUERQUE, A. S. Repetibilidade de descritores foliares em Manihot esculenta Crantz. Raízes e Amidos Tropicais, v. 3, p. 553556, 2007.

ALBUQUERQUE, J. A. A.; SEDIYAMA, T.; SILVA, A. A.; ALVES, J. M. A.; FINOTO, E. L.; ALCÂNTARA NETO, F. Interferência de plantas daninhas sobre a produtividade da mandioca (Manihot esculenta). Planta Daninha, v. 26, n. 2, p. 279-289, 2008.

ALBUQUERQUE, J. A. A.; SEDIYAMA, T.; SILVA, A. A.; ALVES, J. M. A.; FINOTO, E. L.; ALCÂNTARA NETO, F. Desenvolvimento da cultura de mandioca sob interferência de plantas daninhas. Planta Daninha, v. 30, n. 1, p. 37-45, 2012.

ALBUQUERQUE, J. A. A.; SEDIYAMA, T.; SILVA, A. A.; SEDIYAMA, C. S.; ALVES, J. M. A.; ALCÂNTARA NETO, F. Caracterização morfológica e agronômica de clones de mandioca cultivados no Estado de Roraima. Agrária, v. 4, n. 4, p. 388-394, 2009.

ALVAREZ, V.; ALVAREZ, G. A. M. Comparação de médias ou teste de hipóteses? Contraste! Boletim Informativo da SBCS, v. 31, n. 4, p. 24-34, 2006.

ALVES, J. M. A.; ARAÚJO, N. P.; UCHÔA, S. C. P.; ALBUQUERQUE, J. A. A.; SILVA, A. J.; RODRIGUES, G. S.; SILVA, D. C. O. Avaliação agroeconômica da produção de cultivares de feijão-caupi em consórcio com cultivares de mandioca em Roraima. RevistaAgro@mbiente On-line, v. 3, n. 1, p. 15-30, 2009. 
BARBOSA, G. M. Caracterização morfofisiológica de clones de mandioca em Cândido Sales-BA. 2013. 140 f. Dissertação (Mestrado em Agronomia)-Universidade Estadual do Sudoeste da Bahia, Vitória da Conquista, 2013.

CAMPOS, A. L.; ZACARIAS, A. J.; COSTA, D. L.; NEVES, L. G.; BARELli, M. A. A.; SOBRINHO, S. P.; LUZ, P. B. Avaliação de acessos de mandioca do banco de germoplasma da UNEMAT Cáceres - Mato Grosso. Revista Tropical - Ciências Agrárias e Biológicas, v. 4, n. 2, p. 45, 2010.

CARVALHO, P. C. L.; FUKUDA, W. M. G. Estrutura da planta e morfologia. In: SOUZA, L. S.; FARIAS, A. R. N.; MATTOS, P. L. P.; FUKUDA, W. M. G. (Ed.). Aspectos socioeconômicos e agronômicos da mandioca. Cruz das Almas: Embrapa Mandioca e Fruticultura Tropical, 2006. cap. 6. p. 126-137.

EL-SHARKAWY, M. A. Stress-tolerant cassava: the role of integrative ecophysiology-breeding research in crop improvement. Open Journal of Soil Science, v. 2, n. 2, p. 162-186, 2012.

FALQUETO, A. R.; CASSOL, D.; MAGALHÃES JÚNIOR, A. M.; OLIVEIRA, A. C.; BACARIN, M. A. Partição de assimilados em cultivares de arroz diferindo no potencial de produtividade de grãos. Bragantia, v. 68, n. 3, p. 453-461, 2009.

GIERTH, M.; MASER, P. Potassium transporters in plants Involvement in $\mathrm{K}^{+}$acquisition, redistribution and homeostasis. FEBS Letters, v. 581, p. 2348-2356, 2007.

GOMES, C. N.; CARVALHO, S. P.; JESUS, A. M. S.; CUSTÓDIO, T. N. Caracterização morfoagronômica e coeficientes de trilha de caracteres componentes da produção em mandioca. Pesquisa Agropecuária Brasileira, v. 42, n. 8, p. 1121-1130, 2007.
LEDO, C. A. S. Caracterização morfológica da coleção de espécies silvestres de Manihot (Euphorbiaceae-Magnoliophyta) da Embrapa Mandioca e Fruticultura. Cruz das Almas: Embrapa Mandioca e Fruticultura, 2011. 22 p. (Boletim de Pesquisa e Desenvolvimento, 53).

MEHDI, S. M.; SARFRAZ, M.; HAFEEZ, M. Response of rice advance line PB-95 to potassium application in saline-sodic soil. Pakistan Journal of Biological Sciences, v. 10, p. 2935-2939, 2007.

NASSAR, N. M. A.; JUNIOR O. P.; SOUSA, M. V.; ORTIZ, R. Improving carotenoids and amino-acids in Cassava. Recent Patents on Food, Nutrition \& Agriculture, v. 1, n. 1, p. 32-38, 2009.

OLIVEIRA, N. T.; ALVES, J. M. A.; UCHÔA, S. C. P.; RODRIGUES, S. R.; MELVILLE, C. C.; ALBUQUERQUE, J. A. A. Caracterização e identificação de clones de mandioca produzidos em Roraima para o consumo in natura. Revista Agro@mbiente On-line, v. 5, n. 3, p. 188-193, 2011.

OTSUBO, A. A.; SAGRILO, E.; LORENZI, J. O.; GALHARINI, L. G.; OTSUBO, I. M. N.; MATOS, J. S.; UTIDA, D.; FUJINAKA, J. Avaliação de clones de mandioca visando o processamento industrial em Dourados, MS. Raízes e Amidos Tropicais, v. 3, p. 1- 4, 2007.

RAMOS, P. A. S. Caracterização morfológica e produtiva de nove variedades de mandioca cultivadas no Sudoeste da Bahia. 2007. 60 f. Dissertação (Mestrado em Fitotecnia)-Universidade Federal de Viçosa, Viçosa, 2007.

RÓS, A. B.; HIRATA, A. C. S.; DE ARAÚJO, H. U.; NARITA, N. Crescimento, fenologia e produtividade de cultivares de mandioca. Pesquisa Agropecuária Tropical, v. 41, n. 4, p. 552-558, 2011.

Contribuição dos autores: As autoras Deyse Cristina Oliveira da Silva e Ataiza de Andrade Sousa participaram da elaboração do projeto, análise de dados e redação do artigo; os autores Glauber Ferreira Barreto e Cineone Nascimento da Silva auxiliaram na coleta dos dados e redação do artigo. Todas as etapas do trabalho incluindo revisão da redação do projeto e artigo foram orientadas e acompanhadas pelos autores José Maria Arcanjo Alves e Sandra Catia Pereira Uchoa.

Agradecimentos: Os autores agradecem ao CNPq pelo apoio financeiro necessário ao desenvolvimento da pesquisa e à CAPES pela concessão de bolsa.

Fonte de financiamento: Não houve fonte de financiamento.

Conflito de interesse: Os autores declaram não haver conflito de interesse. 